\title{
Article
}

\section{The Assessment of the Severity of COVID-19-Related Anxiety Symptoms in Participants of the University of the Third Age in Poland: A Cross-Sectional Study among Internet Survey Respondents}

\author{
Mateusz Cybulski $^{1, *(\mathbb{D})}$, Urszula Cwalina ${ }^{2} \mathbb{D}$, Dorota Sadowska ${ }^{3}$ and Elżbieta Krajewska-Kułak ${ }^{1}$ (D) \\ 1 Department of Integrated Medical Care, Faculty of Health Sciences, Medical University of Białystok, \\ M. Skłodowskiej-Curie 7A str., 15-096 Białystok, Poland; elzbieta.krajewska-kulak@umb.edu.pl \\ 2 Department of Medical Statistics and Health Informatics, Faculty of Health Sciences, Medical University of \\ Białystok, Szpitalna 37 str., 15-295 Białystok, Poland; urszula.cwalina@umb.edu.pl \\ 3 Department of Endocrinology, Diabetology and Internal Medicine, Faculty of Medicine, Medical University \\ of Białystok, M. Skłodowskiej-Curie 24A str., 15-276 Białystok, Poland; dorotasad@gmail.com \\ * Correspondence: mateusz.cybulski@umb.edu.pl; Tel.: +48-(85)-686-51-08
}

Citation: Cybulski, M.; Cwalina, U.; Sadowska, D.; Krajewska-Kułak, E. The Assessment of the Severity of COVID-19-Related Anxiety Symptoms in Participants of the University of the Third Age in Poland: A Cross-Sectional Study among Internet Survey Respondents. J. Clin. Med. 2021, 10, 3862. https:// doi.org/10.3390/jcm10173862

Academic Editors: Michele Roccella and Allan H. Young

Received: 28 July 2021

Accepted: 26 August 2021

Published: 27 August 2021

Publisher's Note: MDPI stays neutral with regard to jurisdictional claims in published maps and institutional affiliations.

Copyright: (C) 2021 by the authors Licensee MDPI, Basel, Switzerland. This article is an open access article distributed under the terms and conditions of the Creative Commons Attribution (CC BY) license (https:// creativecommons.org/licenses/by/ $4.0 /)$.

\begin{abstract}
Introduction: Fear of infection with SARS-CoV-2 has become widespread. All over the world, since the very beginning of the pandemic, older adults have been considered one of the groups at highest risk of SARS-CoV-2 infection and death due to COVID-19. The aim of the study was to evaluate the severity of anxiety symptoms related to COVID-19 in the older adults who are participants of the Universities of the Third Age in Poland. Material and methods: The study included participants of the University of the Third Age in Poland. A total of 296 persons were enrolled, including 258 women and 38 men. The study was a diagnostic survey, conducted with the use of the following validated psychometric scales: General Anxiety Disorder-7 (GAD-7), Short Health Anxiety Inventory (SHAI), and State-Trait Anxiety Inventory (STAI). Results: In two scales (STAI and SHAI), the mean scores demonstrated mild symptoms indicative of anxiety disorders in the older respondents. Women and men did differ significantly in terms of the scores obtained in STAI X-1 and STAI X-2. Single respondents differed significantly from divorced ones in terms of STAI X-1 scores. Moreover, widows/widowers differed significantly from divorced ones in terms of STAI X-2, and GAD-7 scores. Respondents declaring their financial status as average differed significantly from those declaring their financial status as good in terms of: STAI X-1, STAI X-2, SHAI, and GAD-7 scores. Conclusions: The subjective experience of anxiety symptoms associated with fear of contracting COVID-19 was increased due to the ongoing pandemic, but was not significantly high in the analysed population of older people. COVID-19-related anxiety was significantly more common in lonely individuals and in those of worse financial status. Women and men differed significantly in terms of perceived state anxiety and trait anxiety measured by STAI. More studies addressing COVID-19-related anxiety in older people participating in the Polish Universities of the Third Age are needed to determine a more accurate distribution of this phenomenon in Poland.
\end{abstract}

Keywords: anxiety; COVID-19; fear; general anxiety disorder-7 (GAD-7); older adults; SARS-CoV-2; short health anxiety inventory (SHAI); state-trait anxiety inventory (STAI)

\section{Introduction}

A series of cases of pneumonia of an unknown cause appeared at the end of 2019 in the Chinese province of Wuhan [1]. Several weeks later, in January 2020, the analysis of lab samples revealed a new virus, SARS-CoV-2, that induces an acute respiratory disease [2] which, on 11 February 2020, was referred to as COVID-19 by the World Health Organisation (WHO) Director-General, while on 11 March 2020, the WHO announced the pandemic [3]. 
On 27 July 2021, the number of all identified coronavirus infections in the world reached 194,995,684, of which 4,173,104 patients died due to the infection [4].

Fear of infection with SARS-CoV-2 has become widespread. It is constantly being enhanced by the media reports, where particular emphasis is put on the epidemiological data on mortality and incidence, dramatic information from intensive care units, and news about lacking healthcare resources. An additional factor that increases perceived anxiety is the so-called social distancing principle, which entails restrictions in interpersonal contact [5-7]. The estimated overall prevalence of anxiety in the general population during the COVID-19 pandemic is 25\% [8]. In specific groups, the prevalence of fear of COVID-19 is varied, for example among medical students [9] and healthcare professionals [10] is also $25 \%$, but among college students-36\% [11].

All over the world, since the very beginning of the pandemic, older adults have been considered one of the groups at highest risk of SARS-CoV-2 infection and death due to COVID-19 [12]. The increased risk of contracting the disease and death depends on several factors. Firstly, Poland is one of the top European countries in terms of the number of confirmed COVID-19 cases. As of 27 July 2021, there have been 2,882,327 cases, of which 75,249 were fatal [13]. Moreover, the prevalence of chronic diseases, entailing multimorbidity, is high amongst the older adults all over the world, including in Poland, which increases the risk of severe health-related sequelae, including those related to COVID19 [14]. The prevalence of multimorbidity in Poland is 38.7\% [15].

Although, in principle, COVID-19 may evoke considerable fear among the older adults, there are no sufficient data about the perceived fear resulting from the ongoing COVID-19 pandemic in Poland, especially amongst actively ageing older people. The aim of the study was therefore to evaluate the severity of anxiety symptoms related to COVID-19 among the older adults who are participants of the Universities of the Third Age in Poland. In addition, it was evaluated how selected sociodemographic characteristics affect the level of anxiety symptoms in this subgroup of the older population from Poland. It was assumed that the level of anxiety symptoms among participants of the University of the Third Age will be relatively high. Additionally, we hypothesized that anxiety disorders related to the fear of COVID-19 would occur more frequently among women, single people, and people with lower education.

\section{Materials and Methods}

\subsection{Participants}

The study included participants of the University of the Third Age programme in Poland. A total of 296 persons were enrolled, including 258 women and 38 men. Over half of the respondents $(54.73 \%)$ were in the age range from 60 to 69 years. A similar percentage of the respondents $(51.35 \%$ ) were married. Almost three-quarters of the University of the Third Age participants (71.96\%) had higher education (Master's degree). Nearly one-third of the older adults lived in large cities (over 500,000 inhabitants). The vast majority of the respondents $(91.55 \%)$ were retired. Eighteen respondents had a history of mental disorders. These were: depressive disorders $(n=13)$, bipolar disorder $(n=1)$ and anxiety disorder $(n=4)$.

Detailed sociodemographic characteristics of the respondents are shown in Table 1.

Table 1. Sociodemographic characteristics of the respondents.

\begin{tabular}{cccc}
\hline \multicolumn{2}{c}{ Sociodemographic Feature } & $n$ & $\%$ \\
\hline \multirow{2}{*}{ Sex } & male & 38 & $87.16 \%$ \\
\cline { 2 - 4 } & female & 258 & $12.84 \%$ \\
\hline \multirow{2}{*}{ Age } & $60-69$ years & 162 & $54.73 \%$ \\
\cline { 2 - 4 } & $70-79$ years & 118 & $39.86 \%$ \\
\cline { 2 - 4 } & $80-89$ years & 16 & $5.41 \%$ \\
\hline
\end{tabular}


Table 1. Cont.

\begin{tabular}{|c|c|c|c|}
\hline \multicolumn{2}{|c|}{ Sociodemographic Feature } & $n$ & $\%$ \\
\hline \multirow{5}{*}{ Marital status } & married & 152 & $51.35 \%$ \\
\hline & widow/widower & 75 & $25.34 \%$ \\
\hline & separated & 20 & $6.76 \%$ \\
\hline & divorced & 46 & $15.54 \%$ \\
\hline & single & 3 & $1.01 \%$ \\
\hline \multirow{4}{*}{ Education } & higher & 213 & $71.96 \%$ \\
\hline & secondary & 76 & $25.68 \%$ \\
\hline & technical & 6 & $2.03 \%$ \\
\hline & vocational & 1 & $0.34 \%$ \\
\hline \multirow{5}{*}{ Place of residence } & village & 24 & $8.11 \%$ \\
\hline & town up to 50 thousand & 84 & $28.38 \%$ \\
\hline & town up to 200 thousand & 37 & $12.50 \%$ \\
\hline & city up to 500 thousand & 48 & $16.22 \%$ \\
\hline & city over 500 thousand & 103 & $34.80 \%$ \\
\hline \multirow{5}{*}{ Financial status } & very bad & 1 & $0.34 \%$ \\
\hline & bad & 2 & $0.68 \%$ \\
\hline & average & 114 & $38.51 \%$ \\
\hline & good & 153 & $51.69 \%$ \\
\hline & very good & 26 & $8.78 \%$ \\
\hline \multirow{3}{*}{$\begin{array}{l}\text { Socio-professional } \\
\text { status }\end{array}$} & retirement pensions & 271 & $91.55 \%$ \\
\hline & disability pensions & 4 & $1.35 \%$ \\
\hline & professionally active & 21 & $7.09 \%$ \\
\hline \multirow{16}{*}{ Voivodeship } & Lower Silesian & 32 & $10.81 \%$ \\
\hline & Kuyavian-Pomeranian & 2 & $0.68 \%$ \\
\hline & Lublin & 12 & $4.05 \%$ \\
\hline & Lubusz & 7 & $2.36 \%$ \\
\hline & Łódź & 1 & $0.34 \%$ \\
\hline & Lesser Poland & 67 & $22.64 \%$ \\
\hline & Masovian & 49 & $16.55 \%$ \\
\hline & Opole & 2 & $0.68 \%$ \\
\hline & Subcarpathian & 7 & $2.36 \%$ \\
\hline & Podlaskie & 61 & $20.61 \%$ \\
\hline & Pomeranian & 9 & $3.04 \%$ \\
\hline & Silesian & 23 & $7.77 \%$ \\
\hline & Świętokrzyskie & 4 & $1.35 \%$ \\
\hline & Warmian-Masurian & 16 & $5.41 \%$ \\
\hline & Greater Poland & 1 & $0.34 \%$ \\
\hline & West Pomeranian & 3 & $1.01 \%$ \\
\hline \multirow{2}{*}{$\begin{array}{l}\text { History of mental } \\
\text { disorders }\end{array}$} & yes & 18 & $6.08 \%$ \\
\hline & no & 278 & $93.92 \%$ \\
\hline
\end{tabular}




\subsection{Study Design and Data Collection}

The cross-sectional study was conducted between 1 March and 10 May 2021. The invitations were sent to official e-mail addresses published on the websites of all University of the Third Age chapters in Poland. In this study, the snowball sampling method was employed; it is a non-random sample selection method consisting in recruiting participants by other participants (in our study by the Presidents of Universities of the Third Age or substantive coordinators the Universities that offer such forms of education for the older adults). We used this method in our study as we did not have a contact database for direct students of Universities of the Third Age.

The study involved an online survey created using dedicated software (Webankieta) (Get Feedback, Warsaw, Poland). A link to the survey was included in the invitation e-mails sent to the addresses available on the official University websites. The responses were recorded on the platform, and then downloaded as raw data prepared for a statistical analysis. The mean time to complete the survey was $29 \mathrm{~min}$.

Apart from age and enrolment in the University of the Third Age programme, an additional inclusion criterion was written informed consent to participate in the study. The exclusion criteria were: (1) age $\leq 60$ years; (2) illiteracy (a respondent who had completed at least primary school could participate in the study); and (3) lack of written consent to participate in the study. Each participant could withdraw from the study at any time.

The respondents were chosen by nonprobability sampling. Taking into account the total number of returned questionnaires, the rate of complete filling was $52.7 \%$. The remaining questionnaires were incomplete $(47.3 \%)$.

\subsection{Measures}

The study was a diagnostic survey, conducted with the use of the following validated psychometric scales: General Anxiety Disorder-7 (GAD-7), Short Health Anxiety Inventory (SHAI), and State-Trait Anxiety Inventory (STAI). The authors of the study asked respondents that questions from all standardized research tools used in the study should relate directly to fear of COVID-19.

\subsubsection{State-Trait Anxiety Inventory (STAI)}

The structure of the STAI tool is based on differentiating between anxiety understood as a transitory and situation-dependent state, and anxiety understood as a relatively constant personality trait. In his concept, Spielberger referred to other, earlier studies conducted by R.B. Cattell and I.H. Scheier [16]. They identified two different factors. The first, responsible for situation-dependent score variability, was called "state anxiety". The other, responsible for inter-individual differences, was termed "trait anxiety". The STAI questionnaire consists of two independent parts, each containing 20 statements. The first part, STAI X-1, can evaluate anxiety considered as the current emotional state. This part of the questionnaire is a very sensitive tool. It enables one to trace the dynamics of anxiety even in short time intervals. The other part, STAI X-2, concerns anxiety understood as a personality trait [17]. The patient responds to each statement by choosing one of 4 options. The level of anxiety is expressed as the score resulting from summing up the sub-scores obtained for all individual responses. The scores from each part of the questionnaire may vary from 20 to 80 . The test is interpreted in the following way: the higher the score, the higher the level of perceived anxiety. The score range of 39-40 in state anxiety evaluation suggests the detection of clinical symptoms of anxiety disorder $[18,19]$. The psychometric value of the test makes it useful in group studies. The test reliability, based on the internal consistency coefficient, varies from 0.76 to 0.92 in adult women and men. The construct validity of the $\mathrm{X}-1$ scale ranges from 0.51 for men to 0.57 for women [17].

\subsubsection{Short Health Anxiety Inventory (SHAI)}

The Short Health Anxiety Inventory (SHAI) is an 18-item scale designed to evaluate anxiety in two components of hypochondriasis: probability of disease and negative disease 
consequences. Each of the 18 items contains four statements of which respondents choose one that best describes their feelings over the past 6 months. The responses are scored on a 4-point scale where: 0-no symptoms, 1-mild symptoms, 2-severe symptoms, and 3-very severe symptoms. A cut-off score of 20 was optimal for detecting a severe form of health anxiety, providing the best balance between specificity and sensitivity $[20,21]$.

\subsubsection{Generalised Anxiety Disorder Assessment (GAD-7)}

The GAD-7 is a 7-item scale that is based on the Likert scale. It can be used when evaluating the level of anxiety and the risk of generalised anxiety disorder (GAD). The questions included in the survey evaluate the respondent's feeling of anxiety, tension, nervousness, ability to control these feelings, how easily they appear and how problematic it is to relax. The respondent can obtain 0-3 points for each item, depending on the selected response, i.e., the frequency with which each problem occurs in the respondent $(0-$ not at all; 1 -several days; 2 -more than half the days; 3 -nearly every day). The evaluation concerns the past 14 days. The scores of 5, 10, and 15 indicate mild, moderate, and severe anxiety, respectively. The score of at least 10 indicates that generalised anxiety disorder is very likely [22].

\subsection{Procedure and Ethical Considerations}

The study was carried out in accordance with the recommendations, and was reviewed and approved by the Ethics Committee of the Medical University of Bialystok (No. R-I$002 / 592 / 2019)$. All subjects gave the written informed consent in accordance with the Declaration of Helsinki.

\subsection{Statistical Analysis}

The data were processed with Microsoft Excel 2020 spreadsheet and analysed with Statistica Data Miner C QC PL package. Normal distribution of quantitative variables was checked with the Shapiro-Wilk W-test. As none of the variables was distributed normally, they were analysed using non-parametric tests; the significance of the differences between two groups was verified with the Mann-Whitney U-test, and multiple groups were compared using Kruskal-Wallis ANOVA and appropriate post hoc tests. The associations between the pairs of quantitative variables were analysed based on the Spearman's coefficients of rank correlation. The results of all tests were considered significant at $p<0.05$.

\section{Results}

Table 2 presents descriptive statistics of the standardised research tools applied in this study. In two scales (STAI and SHAI), the mean scores demonstrated mild symptoms indicative of anxiety disorders in the older respondents. In the remaining scale (GAD-7), the means scores were not sufficient to identify the presence of anxiety symptoms related to COVID-19. The detailed values for individual variables are listed in Table 2.

Table 2. Descriptive statistics for the scales applied in the study.

\begin{tabular}{cccccccc}
\hline & $\overline{\boldsymbol{x}}$ & SD & Min. & $\mathbf{Q}_{\mathbf{1}}$ & $\mathbf{M e}$ & $\mathbf{Q}_{\mathbf{3}}$ & Max. \\
\hline STAI X-1 & 44.48 & 11.38 & 20.00 & 37.00 & 43.00 & 53.00 & 77.00 \\
STAI X-2 & 41.83 & 8.59 & 21.00 & 36.00 & 41.50 & 47.00 & 67.00 \\
SHAI & 14.62 & 7.23 & 1.00 & 9.00 & 14.00 & 19.00 & 41.00 \\
GAD-7 & 4.51 & 4.66 & 0.00 & 1.00 & 3.00 & 7.00 & 21.00 \\
\hline
\end{tabular}

Abbreviations: GAD-7—General Anxiety Disorder-7, Max.—maximum, Me—median, Min.—minimum, SDstandard deviation, SHAI-Short Health Anxiety Inventory, STAI-State-Trait Anxiety Inventory, $\mathrm{Q}_{1}$-lower quartile, $\mathrm{Q}_{3}$ - upper quartile, and $\bar{x}$-mean.

Table 3 presents the prevalence of anxiety symptoms among students of University of the Third Age according to the standardized cut-off points. Most of the respondents showed anxiety symptoms measured by the STAI. Similarly, most older adults showed 
minimal or mild anxiety symptoms based on the GAD-7 scores. On the other hand, over $3 / 4$ of the respondents did not show symptoms of anxiety disorders on the basis of the SHAI (Table 3).

Table 3. Prevalence of anxiety symptoms among students of University of the Third Age according to the standardized cut-off points.

\begin{tabular}{|c|c|c|c|}
\hline & Cut-Off Points & $n$ & $\%$ \\
\hline \multirow{2}{*}{ STAI X-1 } & $\begin{array}{c}<40 \\
\text { (no symptoms) }\end{array}$ & 103 & $34.7 \%$ \\
\hline & $\begin{array}{c}\geq 40 \\
\text { (anxiety symptoms) }\end{array}$ & 194 & $65.3 \%$ \\
\hline \multirow{2}{*}{ STAI X-2 } & $\begin{array}{c}<40 \\
\text { (no symptoms) }\end{array}$ & 119 & $40.1 \%$ \\
\hline & $\begin{array}{c}\geq 40 \\
\text { (anxiety symptoms) }\end{array}$ & 178 & $59.9 \%$ \\
\hline \multirow{2}{*}{ SHAI } & $\begin{array}{c}<20 \\
\text { (no symptoms) }\end{array}$ & 226 & $76.1 \%$ \\
\hline & $\begin{array}{c}\geq 20 \\
\text { (anxiety symptoms) }\end{array}$ & 71 & $23.9 \%$ \\
\hline \multirow{5}{*}{ GAD-7 } & $\begin{array}{c}0 \\
\text { (no symptoms) }\end{array}$ & 66 & $22.2 \%$ \\
\hline & $\begin{array}{c}1-4 \\
\text { (minimal symptoms) }\end{array}$ & 109 & $36.7 \%$ \\
\hline & $\begin{array}{c}5-9 \\
\text { (mild symptoms) }\end{array}$ & 83 & $28.0 \%$ \\
\hline & $\begin{array}{c}10-14 \\
\text { (moderate symptoms) }\end{array}$ & 23 & $7.7 \%$ \\
\hline & $\begin{array}{c}15-21 \\
\text { (severe symptoms) }\end{array}$ & 16 & $5.4 \%$ \\
\hline
\end{tabular}

Abbreviations: GAD-7-General Anxiety Disorder-7, SHAI-Short Health Anxiety Inventory, and STAI-StateTrait Anxiety Inventory.

The analysis of the scores obtained using the applied scales in the study group, taking into account the individual sociodemographic variables, indicated that women and men did differ significantly in terms of the scores obtained in STAI X-1 $(p=0.002)$ and STAI X-2 $(p=0.020)$ (Table 4$)$.

Table 4. Impact of sex on the scores obtained in the psychometric scales applied in the study.

\begin{tabular}{cccccc}
\hline & \multicolumn{2}{c}{ Women $(\boldsymbol{n}=\mathbf{2 5 8})$} & \multicolumn{2}{c}{ Men $(\boldsymbol{n}=\mathbf{3 8})$} & \multirow{2}{*}{$\boldsymbol{p}$} \\
\cline { 2 - 5 } & $\overline{\boldsymbol{x}} \pm$ SD & Me & $\overline{\boldsymbol{x}} \pm \mathbf{\text { SD }}$ & $\mathbf{M e}$ & \\
\hline STAI X-1 & $45.26 \pm 11.56$ & 44 & $39.21 \pm 8.39$ & 39 & $0.002 *$ \\
STAI X-2 & $42.27 \pm 8.73$ & 42 & $38.84 \pm 6.88$ & 38 & $0.020^{*}$ \\
SHAI & $14.84 \pm 7.39$ & 14 & $13.08 \pm 5.92$ & 12 & 0.205 \\
GAD-7 & $4.69 \pm 4.82$ & 4 & $3.26 \pm 3.23$ & 2 & 0.195 \\
\hline
\end{tabular}

Abbreviations: GAD-7—General Anxiety Disorder-7, Me—median, $p-p$-value, SD—standard deviation, SHAIShort Health Anxiety Inventory, STAI—State-Trait Anxiety Inventory, $\bar{x}$ - mean, and * — statistically significant.

There were no statistically significant differences between respondents with higher education and those with a different level of education. Nor were there any statistically significant differences between professionally active respondents and pensioners. A number of statistically significant differences were noted for the results of the applied scales in terms of the marital status. The analysis revealed that single respondents differed significantly 
from divorced ones in terms of STAI X-1 scores $(p=0.046)$. Moreover, widows/widowers differed significantly from divorced ones in terms of STAI X-2 ( $p=0.045)$, and GAD-7 scores $(p=0.032)$ (Table 5).

Table 5. Impact of marital status on the scores obtained in the psychometric scales applied in the study *.

\begin{tabular}{|c|c|c|c|c|c|c|c|c|c|c|}
\hline & \multicolumn{2}{|c|}{$\begin{array}{c}\text { Married } \\
\text { (I) }(n=152)\end{array}$} & \multicolumn{2}{|c|}{$\begin{array}{c}\text { Widow/Widower (II) } \\
\quad(n=75)\end{array}$} & \multicolumn{2}{|c|}{$\begin{array}{l}\text { Separated } \\
\text { (III) }(n=20)\end{array}$} & \multicolumn{2}{|c|}{$\begin{array}{c}\text { Divorced } \\
\text { (IV) }(n=46)\end{array}$} & \multicolumn{2}{|c|}{$p$} \\
\hline & $\bar{x} \pm \mathrm{SD}$ & $\mathrm{Me}$ & $\bar{x} \pm \mathrm{SD}$ & Me & $\bar{x} \pm \mathrm{SD}$ & $\mathrm{Me}$ & $\bar{x} \pm \mathrm{SD}$ & Me & K-W & Post hoc \\
\hline STAI X-1 & $44.68 \pm 10.91$ & 43 & $43.07 \pm 11.44$ & 42 & $39.8 \pm 8.41$ & 40.5 & $48.59 \pm 12.91$ & 48 & 0.046 & III-IV: 0.046 \\
\hline STAI X-2 & $41.89 \pm 7.54$ & 42 & $40.41 \pm 8.84$ & 40 & $38.8 \pm 8.68$ & 39 & $45.39 \pm 10.51$ & 46 & 0.021 & II-IV: 0.045 \\
\hline SHAI & $14.01 \pm 6.89$ & 13 & $14.37 \pm 7.12$ & 13 & $14.6 \pm 6.75$ & 15 & $17.04 \pm 8.5$ & 16.5 & 0.1636 & - \\
\hline GAD-7 & $4.72 \pm 4.64$ & 4 & $3.41 \pm 3.87$ & 3 & $3.45 \pm 3.9$ & 2 & $6.24 \pm 5.75$ & 4.5 & 0.017 & II-IV: 0.032 \\
\hline
\end{tabular}

* The table also includes statistically significant results of the post hoc tests; for the remaining comparisons $p>0.05$. Abbreviations: GAD-7-General Anxiety Disorder-7, K-W—Kruskal-Wallis test, Me-median, $p$ - $p$-value, SD—standard deviation, SHAI-Short Health Anxiety Inventory, STAI-State-Trait Anxiety Inventory, and $\bar{x}-$ mean.

Respondents declaring their financial status as average differed significantly from those declaring their financial status as good in terms of: STAI X-1, STAI X-2, SHAI, and GAD-7 scores. Details are included in Table 6.

Table 6. Impact of financial status on the scores obtained in the psychometric scales applied in the study *

\begin{tabular}{|c|c|c|c|c|c|c|c|c|}
\hline & \multicolumn{2}{|c|}{$\begin{array}{l}\text { Very Good (I) } \\
\quad(n=26)\end{array}$} & \multicolumn{2}{|c|}{$\begin{array}{l}\text { Good (II) } \\
(n=153)\end{array}$} & \multicolumn{2}{|c|}{$\begin{array}{l}\text { Average (III) } \\
\quad(n=114)\end{array}$} & \multicolumn{2}{|c|}{$p$} \\
\hline & $\bar{x} \pm \mathrm{SD}$ & Me & $\bar{x} \pm \mathrm{SD}$ & $\mathrm{Me}$ & $\bar{x} \pm \mathrm{SD}$ & Me & $\mathrm{K}-\mathrm{W}$ & Post hoc \\
\hline STAI X-1 & $43 \pm 11.85$ & 41 & $42.84 \pm 10.65$ & 41 & $46.72 \pm 11.83$ & 47 & 0.010 & II-III: 0.011 \\
\hline STAI X-2 & $39.5 \pm 9.58$ & 39 & $40.56 \pm 7.68$ & 40 & $43.82 \pm 8.93$ & 45 & 0.002 & II-III: 0.005 \\
\hline SHAI & $12.92 \pm 7.21$ & 11.5 & $13.71 \pm 6.66$ & 13 & $16.03 \pm 7.49$ & 15 & 0.017 & II-III: 0.035 \\
\hline GAD-7 & $3.96 \pm 4.46$ & 3 & $3.85 \pm 4.25$ & 3 & $5.39 \pm 5.01$ & 4 & 0.023 & II-III: 0.027 \\
\hline
\end{tabular}

* The table also includes statistically significant results of the post hoc tests; for the remaining comparisons $p>0.05$. Abbreviations: GAD-7-General Anxiety Disorder-7, K-W—Kruskal-Wallis test, Me — median, $p$ - $p$-value, SD—standard deviation, SHAI-Short Health Anxiety Inventory, STAI-State-Trait Anxiety Inventory, and $\bar{x}$-mean.

When analysing the obtained data, no statistically significant association was found between age and scores of the individual scales. Moreover, the respondents were divided into subgroups by sex, marital status, level of education, and place of residence, and the associations between age and scale scores were also analysed within these individual subgroups. Taking into account the division by education, the significance was found for the correlation between age and STAI X-1 $(r=-0.140, p=0.042)$ in the group of people with higher education. As for the remaining divisions, the results obtained in the subgroups confirmed the results obtained in the full set analysis and, consequently, no significant correlation between age and scores of the applied scales was found.

The study also involved relationships between the values of all applied scales. It was found that each of the correlation coefficients was positive, high, and statistically significant (Table 7). Moreover, an analogous analysis was performed in subgroups, taking into account sex, marital status, education, and place of residence. All of the resultant correlation coefficients were positive, high, and statistically significant. 
Table 7. Spearman's rank correlations between standardised psychometric scales used in the study.

\begin{tabular}{|c|c|c|c|c|}
\hline & & STAI X-1 & STAI X-2 & SHAI \\
\hline \multirow{2}{*}{ STAI X-2 } & $\mathrm{r}$ & 0.789 & \multirow{2}{*}{ - } & \multirow{2}{*}{ - } \\
\hline & $p$ & $<0.001 *$ & & \\
\hline \multirow{2}{*}{ SHAI } & $\mathrm{r}$ & 0.584 & 0.625 & \multirow{2}{*}{ - } \\
\hline & $p$ & $<0.001 *$ & $<0.001 *$ & \\
\hline \multirow{2}{*}{ GAD-7 } & $\mathrm{r}$ & 0.691 & 0.758 & 0.554 \\
\hline & $p$ & $<0.001$ * & $<0.001$ * & $<0.001$ * \\
\hline
\end{tabular}

Abbreviations: GAD-7—General Anxiety Disorder-7, $p-p$-value, r-Spearman's rank correlation coefficient, SHAI-Short Health Anxiety Inventory, STAI-State-Trait Anxiety Inventory, and * —statistically significant.

\section{Discussion}

This study is one of the first to determine the correlation between various sociodemographic factors and perceived anxiety related to the ongoing COVID-19 pandemic in the older Polish population. It was shown that the actively ageing older people experience various levels of anxiety symptoms related to COVID-19, depending on the applied scales. However, none of the scales yielded sufficiently high results to identify high COVID19-related anxiety, and the set research hypothesis was therefore not confirmed in this study.

Although the present study demonstrated only mild anxiety symptoms in STAI and SHAI scales, other studies among the older adults from other countries have revealed that COVID-19 contributes to the worsening of mental health in this age group, primarily due to anxiety related to death, which is a consequence of this disease [23,24].

In our study, the prevalence of anxiety symptoms as measured by GAD-7 was $41.1 \%$, including $28 \%$ of mild, $7.7 \%$ of moderate, and $5.4 \%$ of severe anxiety symptoms. Another Polish study, conducted using the same tool among university students, found that the prevalence of anxiety was high and was $65 \%$, including $32 \%$ of mild, $21 \%$ of moderate, and $14 \%$ cases of severe anxiety disorder [25]. It is worth noting that higher percentages were recorded among young adults, not seniors. These differences could have been influenced by the timing of the study (young people were examined at the beginning of the pandemic) and the size of the group (the group of students was much larger than the group of seniors).

The present study showed that age was not linked significantly with anxiety related to developing COVID-19. These results are in line with previous studies, both Polish [26] and conducted abroad [27-29], which have shown that age is negatively correlated with anxiety symptoms during the pandemic. The available literature contains publications that did confirm high anxiety in the oldest age groups, particularly in China [30,31].

The present study did not show any statistically significant differences between professionally active respondents and those that finished their career (receiving retirement or disability pensions). The reverse was observed by Mistry et al. [32]. These authors found that older people who were unemployed or retired felt anxious about contracting COVID19 , and about its negative consequences, significantly more often. The same study [32] also confirmed a similar relationship as in the present study, namely that subjects with a worse financial status experienced stronger COVID-19-related anxiety than people with a better financial status.

The present study demonstrated that women were characterised by a higher level of COVID-19-related anxiety than men. The obtained values are in line with evidence provided by other authors confirming that women more often complain about stronger anxiety symptoms compared to men $[25,33,34]$. Other authors have also observed this relationship in their studies; for instance, in the study involving the Chinese population, women reported stronger worries related to developing COVID-19 than men [35]. In the present study, the overrepresentation of women compared to men in the study population could have affected the resulting higher level of anxiety. The finding that female sex is a predictor of anxiety suggests (as does the report of Naharci et al. [36]) that older women are 
more susceptible to mental health risks associated with COVID-19. The previous COVID19-related studies reported mixed results regarding the association between sex and anxiety disorders. Two population-based studies showed that women tend to worry more often and are more susceptible to mental problems [37,38]. A recent literature review suggested that women have a tendency to develop a more psychological anxiety experience [39]. Nonetheless, further studies are needed to reflect sex-based differences in stress exposure related to developing infectious diseases.

In the study conducted by Islam et al. [40], it was shown that generalised anxiety was not significantly correlated with respondents' education-a finding in line with the present study. Regarding educational level, the results revealed that older adults with higher education levels had lower levels of anxiety. This is consistent with the findings reported in Italy [41] and Egypt [42] which showed that lower level of education directly indicates the beginning of the increased pandemic stress. This may be attributed to the fact that education is the foundation for successful coping. On the other hand, some studies suggested that people with higher education tended to be more concerned, perhaps due to a high degree of self-awareness of their well-being [30]. The novel nature of coronavirus disease and changing perceptions about the disease are one of the main factors justifying these opposite results.

The current facts suggest that certain groups of people (for example, older adults) may be especially prone to experiencing generalised anxiety in the initial stages of the COVID-19 pandemic, and further investigations are needed to specify the causes and develop appropriate interventions to improve the public health of the entire population.

\section{Limitations}

The present study does have certain, potential limitations. First, it was a cross-sectional study, based only on a self-reportable survey. Although the applied scales are sensitive tools designed to detect anxiety symptoms, they all focus on subjective symptoms, rather than objective clinical criteria, which poses a risk of false-positive results. Second, the study group was too small to generalise the results to the whole population of Polish older people attending Universities of the Third Age. Third, the study group was overrepresented by women, and therefore the results should be also verified in a larger group of men. However, both the actual rate of University of the Third Age participants and the actual demographic trends in the Polish population distinguish a high rate of women in relation to men. Despite these limitations, the results of this research can be a starting point for further studies addressing anxiety symptoms caused by fear of developing COVID-19 and its sociodemographic determinants amongst participants of Universities of the Third Age. A longitudinal study could provide optimal answers to these questions.

\section{Conclusions}

1. The subjective experience of anxiety symptoms associated with fear of contracting COVID-19 was increased due to the ongoing pandemic, but was not significantly high in the analysed population of older people;

2. COVID-19-related anxiety was significantly more common in lonely individuals (widows/widowers, divorced individuals, and single persons) and in those of worse financial status;

3. Women and men differed significantly in terms of perceived state anxiety and trait anxiety measured by STAI;

4. More studies are needed addressing COVID-19-related anxiety in the older adults participating in the Polish Universities of the Third Age to determine a more accurate distribution of this phenomenon in Poland.

Author Contributions: Conceptualization, M.C.; Data curation, M.C., D.S. and E.K.-K.; Formal analysis, M.C. and U.C.; Funding acquisition, M.C.; Investigation, M.C., D.S. and E.K.-K.; Methodology, M.C. and U.C.; Project administration, M.C.; Writing-original draft, M.C. and U.C.; and 
Writing-review and editing, M.C. and E.K.-K. All authors have read and agreed to the published version of the manuscript.

Funding: The research was financed by the funds from the Medical University of Białystok with a grant no. SUB/3/DN/21/001/3310 awarded by the Polish Ministry of Education and Science in the form of a subvention for maintaining and developing research potential in 2021. The APC was funded by Medical University of Białystok.

Institutional Review Board Statement: The study was conducted according to the guidelines of the Declaration of Helsinki, and approved by the Ethics Committee of the Medical University of Białystok, Poland (No. R-I-002/592/2019).

Informed Consent Statement: Informed consent was obtained from all the subjects involved in the study.

Data Availability Statement: Data are available upon reasonable request.

Acknowledgments: The authors thank the all respondents who participated in the study.

Conflicts of Interest: The authors declare no conflict of interest. The funders had no role in the design of the study; in the collection, analyses, or interpretation of data; in the writing of the manuscript, or in the decision to publish the results.

\section{References}

1. Lu, H.; Stratton, C.W.; Tang, Y.W. Outbreak of pneumonia of unknown etiology in Wuhan, China: The mystery and the miracle. J. Med. Virol. 2020, 92, 401-402. [CrossRef] [PubMed]

2. Huang, C.; Wang, Y.; Li, X.; Ren, L.; Zhao, J.; Hu, Y.; Zhang, L.; Fan, G.; Xu, J.; Gu, X.; et al. Clinical features of patients infected with 2019 novel coronavirus in Wuhan, China. Lancet 2020, 395, 497-506. [CrossRef]

3. World Health Organization: Coronavirus Disease (COVID-19) Pandemic. Available online: https://www.who.int/emergencies/ diseases / novel-coronavirus-2019 (accessed on 27 July 2021).

4. COVID-19 Dashboard by the Center for Systems Science and Engineering (CSSE) at Johns Hopkins University (JHU). Available online: https:/ / gisanddata.maps.arcgis.com/apps/dashboards/bda7594740fd40299423467b48e9ecf6 (accessed on 27 July 2021).

5. Chen, Q.; Liang, M.; Li, Y.; Guo, J.; Fei, D.; Wang, L.; He, L.; Sheng, C.; Cai, Y.; Li, X.; et al. Mental health care for medical staff in China during the COVID-19 outbreak. Lancet Psychiatry 2020, 7, e15-e16. [CrossRef]

6. Yang, Y.; Li, W.; Zhang, Q.; Zhang, L.; Cheung, T.; Xiang, Y.T. Mental health services for older adults in China during the COVID-19 outbreak. Lancet Psychiatry 2020, 7, e19. [CrossRef]

7. Smirni, P.; Lavanco, G.; Smirni, D. Anxiety in Older Adolescents at the Time of COVID-19. J. Clin. Med. 2020, 9, 3064. [CrossRef] [PubMed]

8. Santabárbara, J.; Lasheras, I.; Lipnicki, D.M.; Bueno-Notivol, J.; Pérez-Moreno, M.; López-Antón, R.; De la Cámara, C.; Lobo, A.; Gracia-García, P. Prevalence of anxiety in the COVID-19 pandemic: An updated meta-analysis of community-based studies. Prog. Neuropsychopharmacol. Biol. Psychiatry 2021, 109, 110207. [CrossRef]

9. Lasheras, I.; Gracia-García, P.; Lipnicki, D.M.; Bueno-Notivol, J.; López-Antón, R.; de la Cámara, C.; Lobo, A.; Santabárbara, J. Prevalence of Anxiety in Medical Students during the COVID-19 Pandemic: A Rapid Systematic Review with Meta-Analysis. Int. J. Environ. Res. Public Health 2020, 17, 6603. [CrossRef]

10. Santabárbara, J.; Bueno-Notivol, J.; Lipnicki, D.M.; Olaya, B.; Pérez-Moreno, M.; Gracia-García, P.; Idoiaga-Mondragon, N.; Ozamiz-Etxebarria, N. Prevalence of anxiety in health care professionals during the COVID-19 pandemic: A rapid systematic review (on published articles in Medline) with meta-analysis. Prog. Neuropsychopharmacol. Biol. Psychiatry 2021, $107,110244$. [CrossRef]

11. Li, Y.; Wang, A.; Wu, Y.; Han, N.; Huang, H. Impact of the COVID-19 Pandemic on the Mental Health of College Students: A Systematic Review and Meta-Analysis. Front. Psychol. 2021, 12, 669119. [CrossRef]

12. Xiang, Y.T.; Yang, Y.; Li, W.; Zhang, L.; Zhang, Q.; Cheung, T.; Ng, C.H. Timely mental health care for the 2019 novel coronavirus outbreak is urgently needed. Lancet Psychiatry 2020, 7, 228-229. [CrossRef]

13. Ministerstwo Zdrowia: Mapa Zarażeń Koronawirusem (SARS-CoV-2). Available online: https://www.gov.pl/web/koronawirus/ wykaz-zarazen-koronawirusem-sars-cov-2 (accessed on 21 June 2021).

14. Souza, D.L.B.; Oliveras-Fabregas, A.; Minobes-Molina, E.; de Camargo Cancela, M.; Galbany-Estragués, P.; Jerez-Roig, J. Trends of multimorbidity in 15 European countries: A population-based study in community-dwelling adults aged 50 and over. BMC Public Health 2021, 21, 76. [CrossRef] [PubMed]

15. Bezerra de Souza, D.L.; Oliveras-Fabregas, A.; Espelt, A.; Bosque-Prous, M.; de Camargo Cancela, M.; Teixidó-Compañó, E.; Jerez-Roig, J. Multimorbidity and its associated factors among adults aged 50 and over: A cross-sectional study in 17 European countries. PLoS ONE 2021, 16, e0246623. [CrossRef]

16. Cattel, R.B. Anxiety and motivation: Theory and crucial experiments. In Anxiety and Behavior; Spielberger, C.D., Ed.; Academic Press: New York, NY, USA, 1966; pp. 23-62. 
17. Wrześniewski, K.; Sosnowski, T.; Matusik, D. Inwentarz Stanu i Cechy Leku STAI. Polska adaptacja STAI; Pracownia Testów Psychologicznych Polskiego Towarzystwa Psychologicznego: Warsaw, Poland, 2002.

18. Knight, R.G.; Waal-Manning, H.J.; Spears, G.F. Some norms and reliability data for the State-Trait Anxiety Inventory and the Zung Self-Rating Depression scale. Br. J. Clin. Psychol. 1983, 22, 245-249. [CrossRef]

19. Addolorato, G.; Ancona, C.; Capristo, E.; Graziosetto, R.; Di Rienzo, L.; Maurizi, M.; Gasbarrini, G. State and trait anxiety in women affected by allergic and vasomotor rhinitis. J. Psychosom. Res. 1999, 46, 283-289. [CrossRef]

20. Kocjan, J. Short Health Anxiety Inventory (SHAI)-Polish version: Evaluation of psychometric properties and factor structure. Arch. Psychiatry Psychother. 2016, 18, 68-78. [CrossRef]

21. Abramowitz, J.S.; Deacon, B.J.; Valentiner, D.P. The Short Health Anxiety Inventory: Psychometric Properties and Construct Validity in a Non-clinical Sample. Cognit. Ther. Res. 2007, 31, 871-883. [CrossRef] [PubMed]

22. Spitzer, R.L.; Kroenke, K.; Williams, J.B.; Löwe, B. A brief measure for assessing generalized anxiety disorder: The GAD-7. Arch. Intern. Med. 2006, 166, 1092-1097. [CrossRef]

23. Banerjee, D. The impact of Covid-19 pandemic on elderly mental health. Int. J. Geriatr. Psychiatry 2020, 35, 1466-1467. [CrossRef] [PubMed]

24. $\mathrm{Wu}, \mathrm{B}$. Social isolation and loneliness among older adults in the context of COVID-19: A global challenge. Glob. Health Res. Policy 2020, 5, 27. [CrossRef]

25. Rogowska, A.M.; Kuśnierz, C.; Bokszczanin, A. Examining Anxiety, Life Satisfaction, General Health, Stress and Coping Styles During COVID-19 Pandemic in Polish Sample of University Students. Psychol. Res. Behav. Manag. 2020, 13, 797-811. [CrossRef] [PubMed]

26. Gambin, M.; Sękowski, M.; Woźniak-Prus, M.; Wnuk, A.; Oleksy, T.; Cudo, A.; Hansen, K.; Huflejt-Łukasik, M.; Kubicka, K.; Łyś, A.E.; et al. Generalized anxiety and depressive symptoms in various age groups during the COVID-19 lockdown in Poland. Specific predictors and differences in symptoms severity. Compr. Psychiatry 2021, 105, 152222. [CrossRef] [PubMed]

27. González-Sanguino, C.; Ausín, B.; Castellanos, M.Á.; Saiz, J.; López-Gómez, A.; Ugidos, C.; Muñoz, M. Mental health consequences during the initial stage of the 2020 coronavirus pandemic (COVID-19) in Spain. Brain Behav. Immun. 2020, 87, 172-176. [CrossRef]

28. Jia, R.; Ayling, K.; Chalder, T.; Massey, A.; Broadbent, E.; Coupland, C.; Vedhara, K. Mental health in the UK during the COVID-19 pandemic: Cross-sectional analyses from a community cohort study. BMJ Open 2020, 10, e040620. [CrossRef] [PubMed]

29. Traunmüller, C.; Stefitz, R.; Gaisbachgrabner, K.; Schwerdtfeger, A. Psychological correlates of COVID-19 pandemic in the Austrian population. BMC Public Health 2020, 20, 1395. [CrossRef]

30. Qiu, J.; Shen, B.; Zhao, M.; Wang, Z.; Xie, B.; Xu, Y. A nationwide survey of psychological distress among Chinese people in the COVID-19 epidemic: Implications and policy recommendations. Gen. Psychiatry 2020, 33, e100213. [CrossRef]

31. Tian, F.; Li, H.; Tian, S.; Yang, J.; Shao, J.; Tian, C. Psychological symptoms of ordinary Chinese citizens based on SCL-90 during the level I emergency response to COVID-19. Psychiatry Res. 2020, 288, 112992. [CrossRef]

32. Mistry, S.K.; Ali, A.R.M.M.; Akther, F.; Yadav, U.N.; Harris, M.F. Exploring fear of COVID-19 and its correlates among older adults in Bangladesh. Global Health 2021, 17, 47. [CrossRef]

33. Parlapani, E.; Holeva, V.; Voitsidis, P.; Blekas, A.; Gliatas, I.; Porfyri, G.N.; Golemis, A.; Papadopoulou, K.; Dimitriadou, A.; Chatzigeorgiou, A.F.; et al. Psychological and Behavioral Responses to the COVID-19 Pandemic in Greece. Front. Psychiatry 2020, 11, 821. [CrossRef]

34. McLean, C.P.; Anderson, E.R. Brave men and timid women? A review of the gender differences in fear and anxiety. Clin. Psychol. Rev. 2009, 29, 496-505. [CrossRef] [PubMed]

35. Wang, C.; Pan, R.; Wan, X.; Tan, Y.; Xu, L.; Ho, C.S.; Ho, R.C. Immediate Psychological Responses and Associated Factors during the Initial Stage of the 2019 Coronavirus Disease (COVID-19) Epidemic among the General Population in China. Int. J. Environ. Res. Public Health 2020, 17, 1729. [CrossRef] [PubMed]

36. Naharci, M.I.; Veizi, B.G.Y.; Katipoglu, B.; Tasci, I. Psychological Burden among Community-dwelling Older Adults with and without a History of a Recent Covid-19 Infection. Clin. Gerontol. 2021, 31. [CrossRef]

37. Bobes-Bascarán, T.; Sáiz, P.A.; Velasco, A.; Martínez-Cao, C.; Pedrosa, C.; Portilla, A.; de la Fuente-Tomas, L.; García-Alvarez, L.; García-Portilla, M.P.; Bobes, J. Early Psychological Correlates Associated With COVID-19 in A Spanish Older Adult Sample. Am. J. Geriatr. Psychiatry 2020, 28, 1287-1298. [CrossRef] [PubMed]

38. Sepúlveda-Loyola, W.; Rodríguez-Sánchez, I.; Pérez-Rodríguez, P.; Ganz, F.; Torralba, R.; Oliveira, D.V.; Rodríguez-Mañas, L. Impact of Social Isolation Due to COVID-19 on Health in Older People: Mental and Physical Effects and Recommendations. J. Nutr. Health Aging 2020, 24, 938-947. [CrossRef] [PubMed]

39. Robb, C.E.; de Jager, C.A.; Ahmadi-Abhari, S.; Giannakopoulou, P.; Udeh-Momoh, C.; McKeand, J.; Price, G.; Car, J.; Majeed, A.; Ward, H.; et al. Associations of Social Isolation with Anxiety and Depression During the Early COVID-19 Pandemic: A Survey of Older Adults in London, UK. Front. Psychiatry 2020, 11, 591120. [CrossRef] [PubMed]

40. Islam, M.S.; Ferdous, M.Z.; Potenza, M.N. Panic and generalized anxiety during the COVID-19 pandemic among Bangladeshi people: An online pilot survey early in the outbreak. J. Affect. Disord. 2020, 276, 30-37. [CrossRef] 
41. Di Crosta, A.; Palumbo, R.; Marchetti, D.; Ceccato, I.; La Malva, P.; Maiella, R.; Cipi, M.; Roma, P.; Mammarella, N.; Verrocchio, M.C.; et al. Individual Differences, Economic Stability, and Fear of Contagion as Risk Factors for PTSD Symptoms in the COVID-19 Emergency. Front. Psychol. 2020, 11, 567367. [CrossRef]

42. Fadila, D.; Ibrahim, F.M.; El-Gilany, A.H. Psychological distress among older adults during COVID-19 pandemic: Prevalence and associated factors. Geriatr. Nurs. 2021, 42, 1077-1083. [CrossRef] 